\title{
Isolated Splenie hydatid Disease: A Rare Presentation
}

Sunita Singh, Sonia Gulia, Pansi Gupta, Divya Srivastava, Shubha Lal, Ragini Gahlaut From the Department of Pathology, Pt. B.D.S. Post Graduate Institute of Medical Sciences, Rohtak - 124001, Haryana, India.

\section{Abstract:}

Although splenic involvement alone in hydatid disease is very rare, spleen is the third most common organ involved in hydatid disease. The rarity of splenic hydatid disease poses a diagnostic challenge for clinicians, particularly in non-endemic areas. The hydatid cyst can present as a simple cyst without having the classic serological and imaging features, and can lead to life-threatening complications like anaphylaxis. Hydatid disease of spleen should be considered in differential in every patient in endemic areas with cystic lesion of spleen until proved otherwise.

Key words: Cysts, Splenomegaly, Echinococcusgranulosus, Splenic Diseases, Animals.

Introduction

Hydatid disease is caused by the cestode tapeworm Echinococcus granulosus. It is predominantly prevalent in live-stock rearing areas. Liver (75\%) followed by the lungs (15\%) are the most common sites of involvement in adults [1]. Hydatid cysts involving the spleen are exceptional $(2.5 \%)$. Splenic hydatid being a rare entity, can occur primarily or in association with hepatic, pulmonary or multi-organ hydatidosis. Isolated splenic hydatid disease is very rare [2]. Echinococcus granulosus causes cystic echinococcosis, Echinococcus multilocularis produces multilocular hydatid (alveolar echinococcosis) and other species like Echinococcus vogeli and oligarthus result in polycystic form. In this report, we present the case of an adult female presenting with isolated splenic hydatid disease.
Case Report

A 45 year old female presented with lump abdomen since 5 years along with pain and heaviness in the left hypochondrium that was increasing gradually since last two years. The pain was localized, gradual in onset, moderate in intensity, dull aching in character, associated with a feeling of heaviness and mass in upper abdomen. A physical examination revealed normal vital parameters. Examination of the abdomen revealed splenomegaly. The remainder of the examination was unremarkable. Her routine hematological and biochemical investigations were normal except $6 \%$ eosinophilia. Ultrasonography examination showed multivesicular cysts measuring $10 \times 7 \times 6 \mathrm{cms}$ with internal septation in the left hypochondrium displacing left kidney inferiorly. A clinical diagnosis

\section{Corresponding Author: Dr. Pansi Gupta}

Email: pgdoc1703@gmail.com

Received: March 13,2014 | Accepted: May 2, 2014 | Published Online: May 25, 2014

This is an Open Access article distributed under the terms of the Creative Commons Attribution License (creativecommons.org/licenses/by/3.0)

Conflict of interest: None declared | Source of funding: Nil | DOl: http://dx.doi.org/10.17659/01.2014.0044 
of cystic lesion of spleen was made. Patient underwent exploratory laparotomy and revealed a multilocular cyst in the spleen with dense adhesions of spleen to diaphragm and gastrosplenic ligament. The cyst along with spleen was removed and sent for histopathological examination. The splenectomy specimen weighed 420 gms measuring $10 \times 7 \times 6 \mathrm{cms}$ in size. Grossly a grey white to tan encapsulated cystic area along with normal splenic tissue was seen [Fig.1]. On cut section, cyst was multiloculated and some of the cystic cavities were filled with mucus like fluid. Multiple shiny, translucent walled cystic structures varying in diameter from 1 to $4 \mathrm{cms}$ were also identified within it. These daughter cysts were filled with clear fluid. On histopathology laminated cystic wall, scolices and focal calcification along with normal splenic tissue was seen [Fig.2,3]. On Masson's Trichome stain, hooklets are highlighted [Fig.4]. The final diagnosis of splenic hydatid cyst was made.

\section{Discussion}

Splenic cysts are uncommon entities and accounts for only $0.5-2.0 \%$ of the population [3]. They are usually parasitic in origin and are mostly echinococcal,

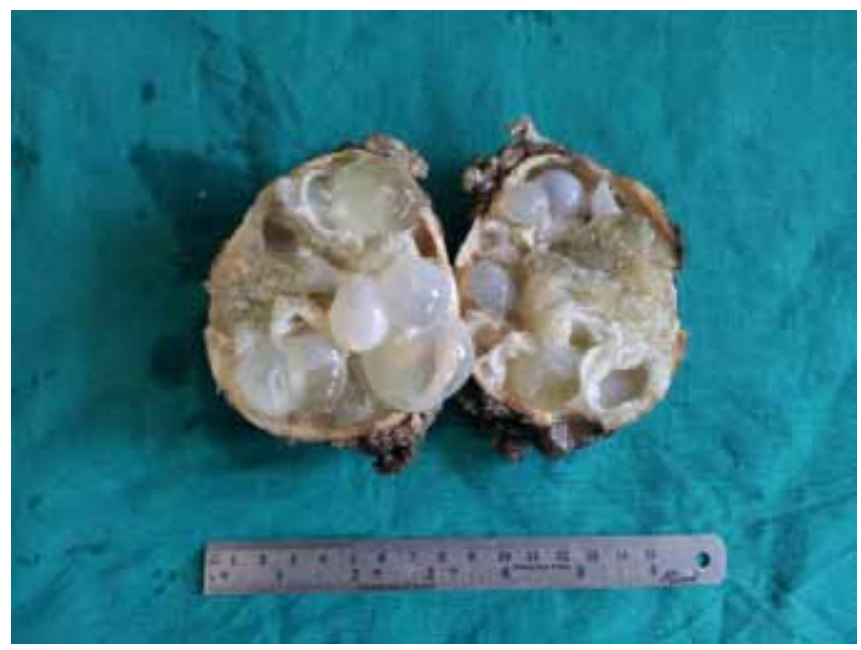

Fig. 1: Gross view of multiple fluid filled vesicles on cut section of spleen. while non-parasitic cysts being categorized as dermoid, epidermoid and pseudocysts [4]. Larvae of Echinococcus granulosus cause hydatid disease in humans. It has a cosmopolitan distribution, being particularly prevalent in sheep and cattle raising areas of the world.

Humans are incidental host and acquire the disease by ingesting highly infective eggs of adult Echinococcus present in the small intestine of the definitive hosts like dogs and canine animals. Human's ingestion of such contaminated food leads to hatching of ova in the gastrointestinal tract. The enclosed embryos are liberated in the duodenum and passed through liver and lungs which act as filters then develop into hydatid cysts. Some escape from these to involve the brain, kidneys, bones and other soft tissues [5]. Infection is usually acquired in childhood and mostly remains asymptomatic. The cyst grows slowly and it may take 5-20 years to grow into a sufficient size $(3-35 \mathrm{cms})$ to cause symptoms of a constant abdominal pain and abdominal lump [6]. Our patient was 45 year lady who was initially asymptomatic but later on presented with a painful mass in the left hypochondrium.

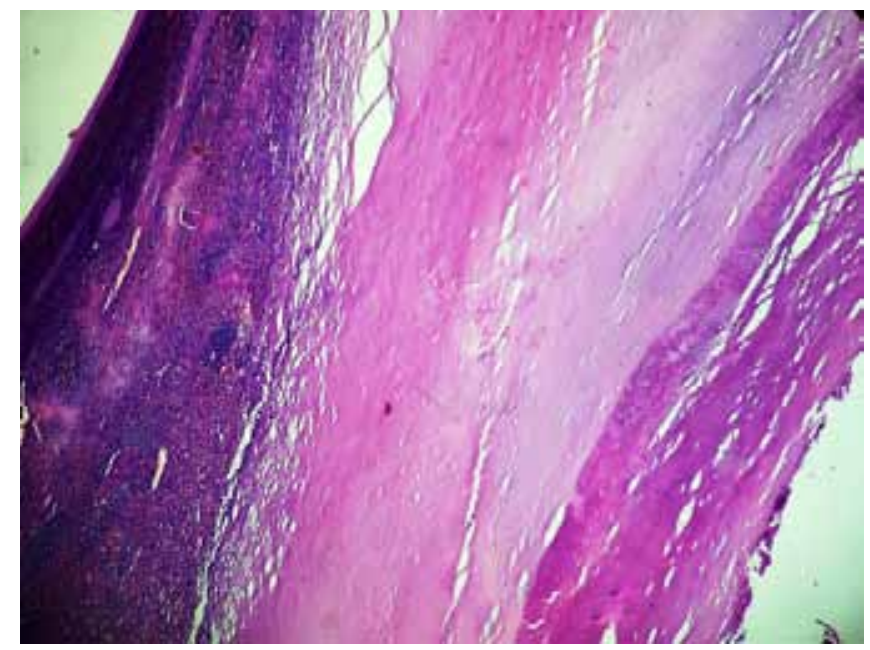

Fig.2: Microscopic view of laminated cyst wall with spleen (H\&E, 100x). 


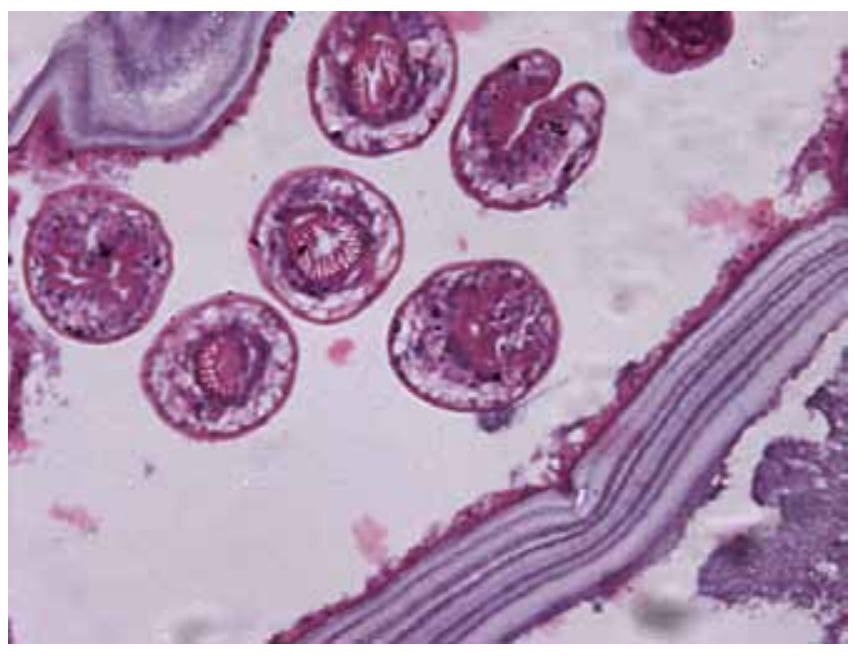

Fig.3: Microscopic view of scolices with hooklets (H\&E, 200x).

Splenic hydatid disease is rare and the incidence is reported between $2-3.5 \%$ by different authors $[7,8]$. Diagnosis relies on radiology and serology. Sonography is helpful, especially in early stages of the disease when the lesion is cystic, in detecting the daughter cysts, cystic membranes, septa and hydatid sand [9]. Preoperative diagnosis of this infection is mandatory in order to prevent any rupture of cyst so as to avoid anaphylactic shock or local recurrence. Since the condition closely resembles a soft tissue tumor on clinical examination, preoperative radiological diagnosis is very important to avoid a biopsy [10].

The differential diagnosis of cystic lesions of spleen includes parasitic echinococcal disease, congenital cyst, intersplenic pancreatic pseudocyst, pseudocyst from splenic trauma, infarcting infection, pyogenic splenic abscess, metastatic diseases and cystic lymphangioma or hemangioma [ 11 l].

Owing to the risk of spontaneous or traumatic rupture, splenic hydatid cysts are usually treated surgically. The standard treatment is total or partial splenectomy. Cyst fluid can be drained with puncture and aspiration to reduce the intracystic pressure,

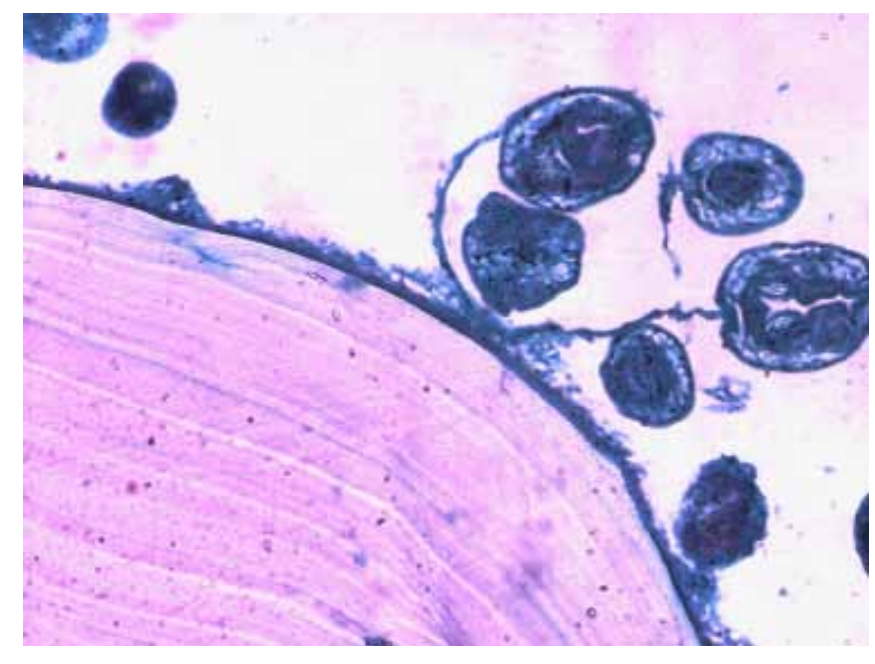

Fig.4: Microscopic view of scolices with hooklets (MT, 200x).

but splenectomy without puncturing the cyst is preferable [12]. We drained the splenic cyst in our patient before splenectomy. Albendazole therapy is the mainstay of treatment in the postoperative follow-up period.

With multiple cysts, multiple initial locations, recurrence in multiple organs and especially in the peritoneum represent a good indication of chemotherapy alone which may also be the first step before a hazardous operation in complicated cases. Albendazole is significantly more effective than mebendazole in the treatment of whole hydatid cysts $(77.9 \%$ vs. $50.6 \%$ respectively). It is usually preferred at an average daily dosage of $15 \mathrm{mg} / \mathrm{kg} /$ day; it must be given continuously. Ideally, preoperative prophylaxis, i.e., albendazole and praziquantal should be started 1 month and 2 weeks prior to surgery respectively or at least 4 days before surgery according to $\mathrm{WHO}$ guidelines. It stabilizes cysts, decreases tension inside the cyst, decrease anaphylaxis and recurrence. However, no controlled long-term studies have ever evaluated the efficacy of chemotherapy to prevent recurrence after surgery, as well as the optimal schedule before and after surgery or PAIR and the risk/benefit of a 
combined treatment with praziquantel. This clearly indicates the absence of consensus and the need for guidelines [13].

\section{Conclusion}

Splenic involvement is an uncommon manifestation of hydatid disease and should be suspected on detection of any splenic cyst especially in endemic areas of the world. Ultrasonography and computed tomography are the most useful diagnostic tools. Surgery is the mainstay of treatment.

\section{References}

1. Kiresi DA, Karabacakoglu A, Odev K, Karakose S. Uncommon locations of hydatid cysts. Acta Radiol 2003;44:622-636.

2. Murtaza B, Gondal ZI, Mehmood A, Shah SS, Abbasi MH, Tamimy MS, et al. Massive splenic hydatid cyst. JCPSP 2005; 15:568-570.

3. Higaki $K$, Jimi $A$, Watanabe J, Kusaba A, Kojiro M. Epidermoid cyst of the spleen with CA 19-9 or carcinoembryonic antigen productions. Am J Surg Pathol 1998; 22:704-708.

4. Kir A, Baran E. Simultaneous operation for hydatid cyst of right lung and liver. Thoraccardiovasc Surgeon 1995;43:62-64.

5. Cuschieri A, Steele RJC, Moosa AR. Infected patients. Essential surgical practice. $4^{\text {th }}$ ed.
Oxford. Butterworth-Heineann; 2000: pp.157160.

6. Wani NA, Tak S, Shah ND, Bashir A, Arif SM. Bullet injury causing rupture of spleen with hydatid Cyst. JK Pract 1998;5:55-56.

7. Sahu SK, Srivastava R, Bahl DV, Sachan PK. Primary hydatid cyst of the spleen: A rare site of presentation. The Internet Journal of Surgery 2008; 1 4(1): ISSN:1528-8242.

8. Kundal VK, Gajdhar M, Kundal R, Sharma C, Agarwal A, Meena A. Giant Epithelial NonParasitic Splenic Cyst. Journal of Case Reports 2013;3(1):106-109.

9. Polat $P$, Kantarci $M$, Alper F, Suma $S$, Koruyusu $M B$, Okur A. Hydatid disease from head to toe. Radiographics 2003;23:475-494.

10. Kune GA, Morris DI. Hydatid disease. In: Schwasyz and Ellis (eds). Maingot's Abdominal operations, 9th edn. Appleton \& Lange, 1989: 1225-1240.

11. Garima D, Varun M, Singh RJ, Neena S. Epithelial cyst of the spleen. J Indian Assoc Pediatr Surg. 201 1;16:18-20.

12. Durgun V, Kapan S, Kapan M, Karabicak I, Aydogan F, Goksoy E. Primary splenic hydatidosis. Dig Surg 2003;20:38-41.

13. Rasheed K, Zarger SA, Telwani AA. Hydatid cyst of spleen: A Diagnostic Challenge. N Am J Med Sci 2013;5:10-20. 